Article

\title{
Biofuel from Balanites aegyptiaca: Optimization of the Feedstock Supply Chain
}

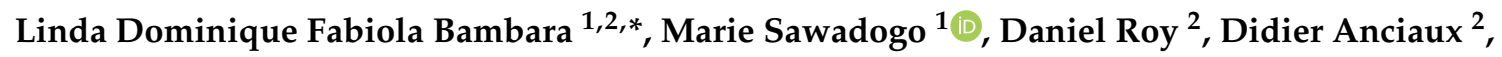 \\ Joël Blin ${ }^{3}$ and Salifou Koucka Ouiminga ${ }^{4}$ \\ 1 Laboratoire Biomasse Energie et Biocarburants, Institut International d'Ingénierie de l'Eau et de \\ l’Environnement, Ouagadougou 01 BP 594, Burkina Faso; marie.sawadogo@2ie-edu.org \\ 2 Laboratoire de Génie Industriel, de Production et de Maintenance, Université de Lorraine, 57000 Metz, \\ France; daniel.roy@univ-lorraine.fr (D.R.); didier.anciaux@univ-lorraine.fr (D.A.) \\ 3 UPR Biomasse-Energie, CIRAD, 34000 Montpellier, France; joel.blin@cirad.fr \\ 4 Laboratoire de Physique et de Chimie de l'Environnement, Université Ouaga 1 Professeur Joseph \\ KI-ZERBO, Ouagadougou 03 BP 7021, Burkina Faso; salif0477@yahoo.com \\ * Correspondence: linda.bambara@univ-lorraine.fr; Tel.: +226-7325-1438
}

Received: 2 October 2018; Accepted: 21 November 2018; Published: 29 November 2018

\begin{abstract}
In arid and semi-arid climates, Balanites aegyptiaca (B. aegyptiaca) is a potential plant to produce oilseed-based biofuels. In this paper an optimization model for a wild biomass supply chain is presented. The model was developed to identify the optimal organization of the supply network that minimizes the cost of supplying the feedstock. It was applied to a case study on a B. aegyptiaca seed supply chain in Burkina Faso. Considering different means of transport and different pre-processing locations, the results show that in contexts such as Burkina Faso's, the most efficient option for the supply of B. aegyptiaca seeds is using animal drawn carts to transport the biomass from the harvest sites to the collection points. Feedstock pre-processing should take place before transport and an improvement in pre-processing operations by mechanical de-hulling could help reduce the cost price of the seeds. The results also show that more than $35 \%$ of the cost price of $B$. aegyptiaca seed is accounted for by transport costs. Pre-processing, handling, and storage costs account for about $50 \%$ of the cost of the seeds.
\end{abstract}

Keywords: biofuel; Balanites aegyptiaca; biomass supply chain; pre-processing; optimization

\section{Introduction}

Access to modern energy services remains limited in sub-Saharan Africa. Indeed, 590 million people in this part of the world still remain without access to electricity in 2017 [1]. More than $80 \%$ of the population without electricity live in rural areas and rely on the traditional use of solid biomass (wood fuel and charcoal) for energy generation [1]. In West Africa Sahelian countries like Burkina Faso, Mali and Niger, the use of traditional biomass account for more than $90 \%$ of primary energy consumption, used mainly for cooking. Consequently, the wood resources are pressured and over harvested, contributing to forest degradation [2]. Another consequence of the low access to energy is the socio-economic underdevelopment. Evidently, energy has been reported to be an essential development component and its consumption is an indicator of the well-being of a population [3].

Based on this energy context, any solution for the development of the energy sector in West Africa as well as in the rest of sub-Saharan Africa that aims to substitute or replace wood fuel is welcome. This could explain the interest of many West African countries in bioenergy $[4,5]$ and particularly in straight vegetable oil (SVO). Evidently, SVO extracted from oilseed crops could be blended with diesel or be used directly as fuel in diesel engines when the quality standards of the oil are respected [6]. 
SVO could also be used in hybrid energy systems consisting of solar photovoltaic and diesel generators like those described by $[7,8]$. They can therefore be used for electrification at the village or country level.

For SVO production in West Africa, especially in West African arid and semi-arid areas where the soil and climatic environment are not suitable to produce the plants commonly used for biofuel production (like jatropha, soybean or rapeseed), Balanites aegyptiaca (B. aegyptiaca) could be an alternative feedstock. B. aegyptiaca, which has already been targeted for the production of oilseed-based biofuels $[9,10]$ is a drought-resistant tree that can grow under varied ecological conditions (e.g., $100 \mathrm{~mm}$ to $1000 \mathrm{~mm}$ of rain per year) [11]. The tree produces fruits that each weigh 5 to $8 \mathrm{~g}$. The fruit consists of an epicarp (5 to $9 \%$ of its weight), an edible mesocarp or pulp (28 to $33 \%$ of its weight), and an endocarp (49 to $54 \%$ of its weight). The endocarp or hull surrounds the seed ( 8 to $12 \%$ of the weight of the fruit) [12-14]. The seed contains between $46 \%$ and $55 \%$ of its weight in vegetable oil [15]. B. aegyptiaca is particularly abundant in arid and semi-arid regions, mainly in sub-Saharan and Sahelian regions such as the Sahelian region of Africa, the Middle East, and South Asia [12]. In these regions, the plant is one of the main plant species [16] and the trees grow wild with no irrigation, fertilization, or care. These characteristics of wild non-cultivated products, also called non timber forest product (NTFP), described by [17] in [18] make B. aegyptiaca seeds an attractive biomass for SVO production.

In addition to the attractive characteristics described above, some authors who investigated the process of B. aegyptiaca oil transeterification for biodiesel production $[19,20]$ and studied the use of $B$. aegyptiaca as a fuel for diesel engines [21-23] showed that B. aegyptiaca biodiesel can be used in a diesel engine as an alternate diesel. Some of these authors also concluded that B. aegyptiaca is a promising feedstock for oilseed-based biofuel production [21]. However, despite these interesting results, none of these authors has assessed the supply of B. aegyptiaca feedstock, which is one of the essential elements in the large-scale production of biofuels.

Indeed, as it is a wild plant, the operations involved in the B. aegyptiaca seed supply chain, which include collection, pre-processing, storage, and transport, can be complex and expensive due to the scattered and irregular distribution of the trees. This is why one of the main obstacles to the commercial exploitation of B. aegyptiaca fruits or nuts (the endocarp containing the seed) is the difficulty of obtaining adequate and regular supplies of the fruits [24]. This is a common feature of all bioenergy production systems to such an extent that in recent years, it is widely accepted that the complex and multi-faceted supply chains of bioenergy production systems call for careful consideration $[25,26]$. Thus, for a profitable and competitive exploitation of B. aegyptiaca for biofuel production, it is important to pay particular attention to the feedstock supply chain. This ensures that the biofuel production unit will be supplied with feedstock of the required quality, quantity, within appropriate periods and at acceptable costs. In addition, a clever feedstock supply chain involving the population may become an income source as well as a growth factor.

The aim of this study was thus to develop a mathematical model for determining the optimal supply network configuration that could minimize the costs of wild oilseed biomass supply. The model has been applied to the B. aegyptiaca seed supply and has been developed by factoring in West Africa's climate, which is characterized by the weak development of infrastructures dedicated to feedstock supply. Depending on the choices of the decision makers in the supply chain, the model could be used to guarantee the profitability of the biofuel production chain while ensuring that all the stakeholders receive a fair remuneration for their work. To the best of our knowledge, this paper is one of the first to study the supply of wild biomass growing in arid climates for biofuel production. It is also one of the first to assess the costs of supplying B. aegyptiaca feedstock and to propose a model for an optimal supply for biofuel production in a West African context. The optimal supply network configuration not only presents a way to organize feedstock harvesting, it also delivers the biofuel production unit in a cost-effective way that reduces both harvesting and logistics (pre-processing, storage, handling and transport) costs. 
The remainder of this paper comprises a description of the mathematical model, its implementation on a case study in Burkina Faso, a description of the obtained results, and a discussion of their implications. After this discussion, future directions are provided.

\section{Methodology}

The model proposed in this paper is a mixed integer linear program (MILP) for decisions related to the configuration of a wild oilseed crop supply chain. These decisions concern the location and the allocation of biomass harvesting sites and of the biomass collection points. They also concern the location of the pre-processing operations and the quantities of feedstock to be transported, handled, pre-processed, and stored.

\subsection{The Problem and Assumptions}

The system to be optimized is the B. aegyptiaca seed supply chain for SVO production. The supply network comprises biomass harvesting sites, biomass collection points, one SVO production unit, and infrastructures needed to harvest, transport, store, and pre-process B. aegyptiaca fruits. The sites mentioned above are linked by a road network. Figure 1 is a schematic representation of the supply network. Biomass harvesting sites are sites where B. aegyptiaca trees are well represented.

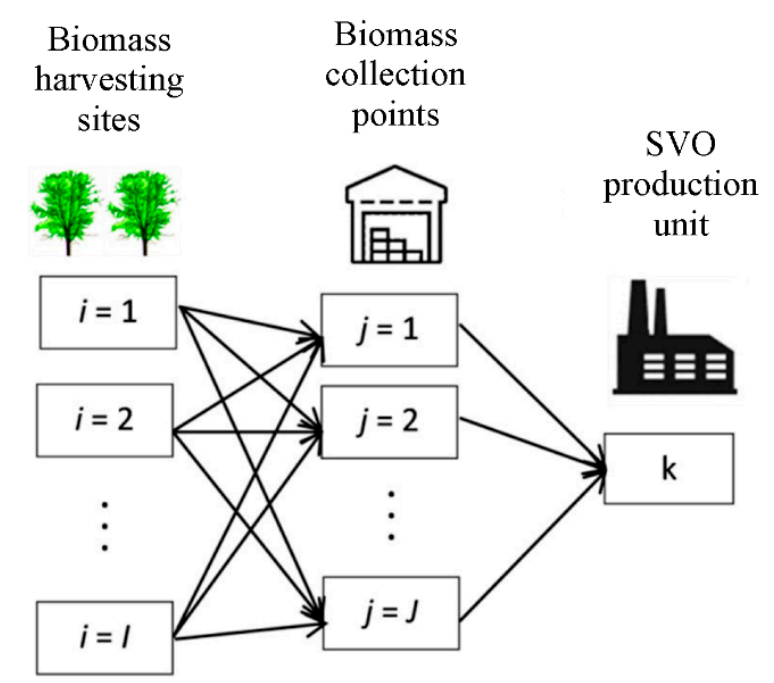

Figure 1. Schematic diagram of the supply network structure with the possible allocations of the sites.

The SVO production unit is located in a Sahelian region in which B. aegyptiaca trees are abundant and where there is a periodic demand for biofuel. This periodic demand for SVO defines the minimum processing capacity of the SVO production unit.

Several biomass harvesting sites are scattered throughout the region around the SVO production unit, and it is assumed that these biomass harvesting sites are able to supply the demand for feedstock of the biofuel production unit.

To facilitate the delivery of the seeds to the biofuel production unit (mainly the labor needed to load, unload, and weigh the feedstock), all the harvested feedstock must pass through a collection point. Indeed, collection points make it possible to bring together large amounts of feedstock, and due to geographical constraints, several potential collection points are selected in advance. Each collection point is characterized by a set of means for biomass transportation, a maximum capacity, and a minimum demand for feedstock. The harvested fruits must be pre-processed. B. aegyptiaca pre-processing is a set of post-harvest operations, which consist of depulping, de-hulling, cleaning, drying, and optional crushing. It can be performed to reduce the quantity (volume or weight) of the material to be transported, to prevent deterioration of the feedstock quality during its transportation and storage, to facilitate and improve SVO extraction. There are two possible locations 
for pre-processing: at the biomass collection points or at the biofuel production unit. Depending on the location of pre-processing operations, the biomass transported and stored can be the non-pretreated biomass (fruits) or the pretreated biomass (seeds). When pre-processing takes place at the collection points, fruits are transported between the biomass harvesting sites and the collection points, and seeds are transported between the collection points and the biofuel production unit. When pre-processing takes place at the biofuel production unit, fruits are transported through the whole supply network.

\subsection{Mathematical Formulation}

The mathematical formulation of the problem consists of an objective function to minimize (1) and a set of constraints (2) to (20). The objective function is made up of feedstock harvesting, transport, pre-processing, storage, and handling (loading and unloading) costs. All these costs take the variable and fixed costs of the operation into account. The elements of the mathematical model are described below (parameters and equations), Table 1 (sets) and in Table 2 (variables).

Table 1. Sets.

\begin{tabular}{cc}
\hline Sets & Index \\
\hline Biomass harvesting sites & $i$ \\
Biomass collection points & $j$ \\
Biofuel production unit & $k$ \\
Means of transport & $m$ \\
Location of pre-processing & $p$ \\
\hline
\end{tabular}

Table 2. Variables.

\begin{tabular}{ccc}
\hline Variables & Description & Domain \\
\hline$S_{i}$ & Surface area of a biomass harvesting site $i$ & $\mathrm{R}+$ \\
\hline$y_{i}$ & Selection of a biomass harvesting site $i$ & $\{0,1\}$ \\
\hline$y_{j}$ & Selection of a collection point $j$ & $\{0,1\}$ \\
\hline$y_{p}$ & Decision on the location of pre-processing & $\{0,1\}$ \\
\hline$Q_{i, j}$ & $\begin{array}{l}\text { Quantity of feedstock to be transported from a } \\
\text { biomass harvesting site } i \text { to a collection point } j\end{array}$ & $\mathrm{R}+$ \\
\hline$Q_{j, p}$ & $\begin{array}{r}\text { Quantity of feedstock collected at a collection point } j \\
\text { if the location of the pre-processing } p \text { is chosen. }\end{array}$ & $\mathrm{R}+$ \\
\hline$Q_{j, k, p}$ & $\begin{array}{c}\text { Quantity of feedstock to be transported from a } \\
\text { collection point } j \text { to the biofuel production unit } k \text { if } \\
\text { the location of pre-processing } p \text { is chosen. }\end{array}$ & $\mathrm{R}+$ \\
\hline
\end{tabular}

\subsubsection{Parameters}

Feedstock demand parameters:

$Q_{k}$ is the annual demand for seed of the biofuel production unit. This demand includes feedstock losses that may occur during the supply.

$\alpha$ is the remaining fraction of feedstock after pre-processing.

$Q_{k, p}$ is the quantity of feedstock expected at the biofuel production unit depending on the location of the pre-processing.

$\mathrm{Qmin}_{j}$ is the minimum quantity of feedstock required at a collection point.

Qmax $_{j}$ is the maximum capacity of a collection point.

Feedstock harvesting and collection parameters:

$S T_{i}$ is the total surface area of a biomass harvesting site. 
Rend $_{i}$ is the territorial seed yield of a biomass harvesting site. The territorial seed yield is the ratio of the total potential seed production at the biomass harvesting site to the surface area of the biomass harvesting site.

$\vartheta$ is the fruits picking rate.

$C h_{i}$ is the unitary harvesting cost.

$W$ is the daily pay for harvesting workers.

$\mathrm{Hr}$ is the prescribed number of work hours per day.

$N T_{i}$ is the number of $B$. aegyptiaca trees at each biomass harvesting site.

Prod is the annual amount of fruits produced by a B. aegyptiaca tree.

$f$ is the maximum number of collection points that can set up.

$a_{i, j}$ defines the potential allocation of a biomass harvesting site $i$ to a collection point $j$.

"at the BPU" is the location of the pre-processing at the biofuel production unit.

"at the $C P$ " is the location of the pre-processing at the collection points.

Feedstock pre-processing handling and storage parameters:

$\mathrm{Hand}_{p}$ is the unitary handling cost depending on the pre-processing location.

$S_{t o r}$ is the unitary storage cost depending on the pre-processing location.

$C f_{p}$ is the total pre-processing fixed costs depending on the location of pre-processing.

$C v_{p}$ is the total pre-processing operating costs depending on the location of pre-processing.

Transportation parameters:

$d_{i, j}$ is the distance between a biomass harvesting site $i$ and a collection point $j$.

$d_{j, k}$ is the distance between a collection point and the biofuel production unit.

$x_{i, m}$ is a binary parameter that defines if the means of transport $m$ is available in a the collection point $j$.

$\tau$ is a tortuosity factor. The tortuosity factor refers to the ratio of the actual travel distance by road to the shortest distance as the crow flies [27].

$C_{m}$ is the unit transport cost for the means of transport $m$ and $C_{\text {truck }}$ is the unit transport cost of the truck.

$P r_{m}$ and $P_{\text {truck }}$ are the fixed costs of the means of transport $m$ and of the truck.

\subsubsection{Equations}

$$
\begin{gathered}
\operatorname{Min} \sum_{i} C h_{i} \cdot S_{i}+\sum_{i, j, p, m} Q_{i, j} \cdot d_{i, j} \cdot \tau \cdot C_{m} \cdot x_{i, m}+\sum_{i, m} \operatorname{Pr}_{m} \cdot x_{i, m} \cdot y_{i}+ \\
\sum_{j, k, p} Q_{j, k, p} \cdot d_{j, k} \cdot \tau \cdot C_{t r u c k}+\sum_{j} \operatorname{Pr}_{\text {truck }} \cdot y_{j}+\sum_{p, j, k} \operatorname{Hand}_{p} \cdot Q_{j, k, p}+\sum_{p, j, k} \operatorname{Stor}_{p} \cdot Q_{j, k, p}+ \\
\sum_{p} C f_{p} \cdot y_{p}+\sum_{p} C v_{p} \cdot y_{p} \\
S_{i} \leq S T_{i} \cdot y_{i} \forall i \\
Q_{k, p}=Q_{k} \rightarrow p=\text { "at the BPU" } \forall p, k \\
Q_{k, p}=Q_{k} \cdot \alpha \rightarrow p=\text { "at the } C P^{\prime \prime} \forall p, k \\
\sum_{i, j} Q_{i, j} \cdot a_{i, j} \geq \sum_{k} Q_{k} \\
\sum_{j} Q_{i, j} \leq S_{i} \cdot \operatorname{Rend}_{i} \forall i \\
Q_{i, j} \leq S_{i} \cdot \operatorname{Rend}_{i} \cdot y_{i} \forall i, j \\
\sum_{i, j} Q_{i, j} \cdot a_{i, j} \leq S T_{i} \cdot \operatorname{Rend}_{i} \cdot y_{j} \\
\sum_{j} Q_{i, j} \cdot a_{i, j} \geq y_{i} \forall i \\
\sum_{i} Q_{i, j} \leq \operatorname{Qmax}_{j} \cdot y_{j} \forall j \\
\sum_{i} Q_{i, j} \geq \operatorname{Qmin}_{j} \cdot y_{j} \forall j
\end{gathered}
$$




$$
\begin{gathered}
Q_{j, p}=\sum_{i} Q_{i, j} \cdot a_{i, j} \rightarrow p=\text { "at the BPU “ } \forall j, p \\
Q_{j, p}=\sum_{i} Q_{i, j} \cdot a_{i, j} \cdot \alpha \rightarrow p=\text { "at the CP" } \forall j, p \\
\sum_{k} Q_{j, k, p}=Q_{j, p} \forall j, p \\
\sum_{k, p} Q_{j, k, p} \geq y_{j} \forall j \\
\sum_{j, k} Q_{j, k, p}=\sum_{k} Q_{k, p} \cdot y_{p} \forall p \\
\sum_{j} y_{j} \leq f \\
\sum_{p} y_{p}=1 \\
\operatorname{Ch}_{i}=\left(\operatorname{Rend}_{i} \cdot W\right) /(\vartheta \cdot H r) \\
\operatorname{Rend}_{i}=\operatorname{Prod}_{\mathrm{N}} \mathrm{NT} T_{i} / S T_{i}
\end{gathered}
$$

Equation (2) ensures that the surface area used by each selected biomass harvesting site does not exceed the available surface area of each biomass harvesting site. Equations (3) and (4) calculate the quantity of feedstock required at the biofuel production unit depending on the location of pre-processing. Equation (5) ensures that the sum of the quantities of feedstock harvested and transported between the chosen biomass harvesting sites and the selected collection points satisfy the quantity of feedstock required by the biofuel production unit. Equations (6) to (9) ensure that the quantities of feedstock transported from the selected biomass harvesting sites to the selected collection points do not exceed the quantities of feedstock that can be harvested at each biomass harvesting site. Equation (10) ensures that the maximum capacity of a selected collection point is not exceeded. Equation (11) ensures that the minimum demand of each selected collection point is satisfied. Equations (12) and (13) calculate the quantity of feedstock to be transported between each selected collection point and the biofuel production unit depending on the choice of the location of pre-processing. Equations (14) to (16) ensure that the quantities of feedstock transported between the selected collection points and the biofuel production unit satisfy the demand of the biofuel production unit depending on the location of pre-processing. Equation (17) ensures that the number of chosen collection points does not exceed the maximum number of collection points needed. Equation (18) ensures that only one pre-processing location is chosen. Equation (19) calculates the unitary costs of harvesting at a biomass harvesting site. Equation (20) calculates the territorial seed yield of a biomass harvesting site.

\section{Case Study}

The model was implemented on a theoretical case study of B. aegyptiaca seed supply chain. Only the number and location of the sites in the supply network are theoretical. They have been randomized into value ranges reflecting reality in Burkina Faso. Costs and other data, etc. reflect the reality. Therefore, calculated costs reflect the real costs that could be observed in Burkina Faso. The randomization of the locations and the number of sites does not prevent the results of the model from reflecting reality in Burkina Faso. Indeed, for a given real case, there is no guarantee that the supply network configuration will follow a particular logic. Yet our model must be able to treat a supply network, whatever its configuration.

The considered biofuel production unit is in a region where an electricity company has a SVO demand of about 66,500 L/year. This SVO must feed diesel engines coupled to alternators for producing electricity. $66,500 \mathrm{~L}$ of SVO corresponds to a seed demand 200 tons, if it is considered that B. aegyptiaca seeds have an oil content of $46 \%$ and that the press used has an extraction efficiency of $65 \%$. The oil density considered is $900 \mathrm{~kg} / \mathrm{m}^{3}$. The need for fruits is 2000 tons, if it is considered that seeds represent $10 \%$ of the dry fruit weight.

Around the biofuel production unit several B. aegyptiaca fruit harvesting sites and several potential collection points have been identified. For a potential collection point to be selected, it must be able to 
collect at least 10 tons of biomass, which represent the load capacity of the trucks usually used for the transport of goods in Burkina Faso. The maximum capacity of each collection point is unlimited.

A fruit productivity per tree of $52 \mathrm{~kg}$ was retained for all the biomass harvesting sites [28]. A B. aegyptiaca tree density ranging from 25 trees/ha to 40 trees/ha was randomly distributed to each of the biomass harvesting sites. According to [29], a density ranging from 25 to 50 trees per ha is acceptable for a region where B. aegyptiaca is well represented.

The harvesting cost per hectare was calculated based on the corresponding labor cost. It was consequently calculated based on a fruit picking rate of $9.24 \mathrm{~kg} / \mathrm{h}$ found by [30] for a tree density of 20 trees/ha and a fruit yield of $545.43 \mathrm{~kg} / \mathrm{ha}$. A man-day is assumed to be $8 \mathrm{~h}$. The minimum daily wage for farm workers is 1363.91 XOF/day in Burkina Faso (XOF is West African CFA francs). Fruit harvesting is done by hand or using worn household containers such as buckets. Therefore, harvesting equipment purchasing costs are not included in the feedstock cost price calculation.

Carts pulled by donkeys and motor tricycles are considered for transporting the feedstock between harvesting sites and collection points. Old trucks are considered for feedstock transportation between collection points and the biofuel production unit. The unit transport cost by cart and tricycle are estimated on the basis of the driver's minimum wage, the maximum load per trip, the velocity of each means of transport and fuel consumption for the tricycle. For carts, a maximum load is about 0.5 tons/trip [31] and the maximum traveling distance covered in a day is $20 \mathrm{~km}$ when considering a velocity of $5 \mathrm{~km} / \mathrm{h}$ [31] and an 8-h work day. For tricycles, the maximum load is 1.1 ton and its fuel consumption is $3.5 \mathrm{~L} / 100 \mathrm{~km}$ [30]. The maximum distance covered in a day is $160 \mathrm{~km}$ considering a velocity of $40 \mathrm{~km} / \mathrm{h}$ and an 8 -h work day. For trucks, the unit transport cost is $52 \mathrm{XOF} /$ ton.km for unpaved roads [32]. Its maximum load is about 10 tons. The costs for each means of transport are listed in Table 3. Only fixed costs arising from the transport of B. aegyptiaca fruits or seeds were calculated, as in rural areas in West Africa, the means of transport are not reserved for a single activity. In this case study, it has been considered that the means of transport are used only from October to December, i.e., three months per year, for the biofuel production unit supply. This period of three months is in the ripening period of the B. aegyptiaca fruits, which according to [11], lasts from October to February.

Concerning the supply network and number, the geographical coordinates of the biomass harvesting sites were randomized over an area with a radius of $50 \mathrm{~km}$. The resulting supply network was used for the whole study. The surface area value of each biomass harvesting site was set to 10 ha. All distances are Euclidean distances to which a tortuosity factor was applied. With no knowledge of the road network in the study area, the value of the tortuosity factor was set to $\sqrt{ } 2$ (it was considered that the straight-line distance is the diagonal of a square, the sides of which represent the actual path) [33].

Pre-processing consists of the depulping and de-hulling of B. aegyptiaca fruits. Due to the difficult access to electricity in rural areas in Burkina Faso, and due to the large quantities of biomass to be collected at the biofuel production unit, it was assumed that pre-processing is manual when it takes place at the collection points and motorized when it takes place at the biofuel production unit. Manual pre-processing involves soaking fruits in water for three days and washing off the pulp to obtain nuts. Nuts are sun-dried for several hours. Seeds are obtained by cracking nuts with a hard, solid object on top of a hard, flat surface.

Pre-processing costs were calculated based on their operating parameters. The manual pulping and de-hulling operating parameter is $2.5 \mathrm{~kg} /$ day per person [34]. Motorized pulping operating parameters are $278.7 \mathrm{~kg} / \mathrm{h}$ per two persons, $30 \mathrm{kWh} / \mathrm{t}$ and $2125 \mathrm{~L} / \mathrm{t}$ (water consumption) and motorized de-hulling operating parameters are $1009.5 \mathrm{~kg} / \mathrm{h}$ per two persons and $30 \mathrm{kWh} / \mathrm{t}$ [30]. Water costs $1091 \mathrm{XOF} / \mathrm{m}^{3}$ (Burkina Faso Water Company in 2017) and electricity costs $114 \mathrm{XOF} / \mathrm{kWh}$ (Burkina Faso Electricity Company in 2017). All the pre-processing machines considered have a lifespan of 10 years and their investment cost is amortized using the declining balance method at a rate of $5 \%$. Unitary costs for each type of pre-processing are described in Table 4. 
At the collection points, biomass is deposited in polypropylene bags before the bags are transported and stored at the biofuel production unit. The handling for a bag full of biomass cost is $100 \mathrm{XOF}$ [35]. The storage cost is assumed to be equal to the cost of the bags in which the biomass is bagged for transport. This storage cost amounts to $250 \mathrm{XOF}$ for a bag full of biomass [35,36]. A full bag weighs $60 \mathrm{~kg}$ if it contains fruit and $70 \mathrm{~kg}$ if it contains seeds.

Four different scenarios were designed to observe the effects of the location of pre-processing and the effects of the means of transport on the supply costs.

In scenario 1, carts pulled by donkeys are used to transport fruits from the harvesting sites to the collection points and two pre-processing locations (at the collection points and at the biofuel production unit) are possible. In scenario 2, motor tricycles are used to transport the fruits from the harvesting sites to the collection points and the pre-processing locations options are the same as in scenario 1. In scenario 3, carts pulled by donkeys are used to transport the feedstock from the biomass harvesting sites to the collection points and only one pre-processing location (at the biofuel production unit) is possible. In scenario 4 , motor tricycles are used to transport the feedstock from the biomass harvesting sites to the collection points and pre-processing location options are the same as in scenario 3.

In the four scenarios, the maximum number of collection points that can be opened is constant and equal to the total number of potential collection points. After determining the scenario with the lowest feedstock cost price at the biofuel production unit gate, this scenario was run again but the value of the parameter $f$ in Equation (19) was varied from 35 to 1 . The objective was to observe the influence of the reduction in the maximum number of collection points that can be opened on the supply costs and on the network configuration. This reduction could occur when some constraints appear (inaccessibility of a collection point by truck for example).

Table 3. Attributes of the means of transport.

\begin{tabular}{cccc}
\hline & Tricycle & Cart & Truck \\
\hline Interest rate $\%$ & 0.05 & 0.05 & 0.05 \\
Life time (years) & 5 & 5 & 10 \\
Price (XOF) & $1,000,000$ & 130,000 & $4,000,000$ \\
Fixed cost (XOF) & 57,744 & 7507 & 129,505 \\
Unitary cost (XOF/ton.km) & 27 & 136 & 52 \\
\hline
\end{tabular}

Table 4. Pre-processing costs (calculated by the authors based on operating parameters).

\begin{tabular}{cccc}
\hline Type & Manual & \multicolumn{2}{c}{ Motorized } \\
\hline Operations & Pulping and De-Hulling & Pulping & De-Hulling \\
\hline Labor $($ XOF/t) & 54,560 & 1225 & 340 \\
Electricity $(\mathrm{XOF} / \mathrm{t})$ & - & 3420 & 3420 \\
Water $(\mathrm{XOF} / \mathrm{t})$ & - & 2320 & - \\
Operating costs $(\mathrm{XOF} / \mathrm{t})$ & 54,560 & 6965 & 3760 \\
Fixed costs for one machine (XOF/year) & - & 485,645 & 679,900 \\
\hline
\end{tabular}

\section{Results and Discussion}

The model was implemented and solved in the optimization software Xpress IVE 7.9. The experiments were performed on an Intel Core i7-5500U CPU $2.4 \mathrm{GHz}$ with 8 GB RAM on a 64-bit platform. The solution was obtained in less than five minutes using the branch and bound algorithms available in the software solver.

The model determines the number of biomass harvesting sites and the optimal surface area to be harvested; the number, location and allocation of biomass harvesting sites; the number, location and allocation of collection points; the quantities of fruit to be harvested and pre-processed; the location of pre-processing if more than one location is possible; the quantities of fruit or seed to be transported, 
handled and stored depending on the pre-processing location; total supply costs (optimal costs of harvest, transport, pre-processing, storage, and handling).

The results of the implementation of the four scenarios are presented and discussed below. These results concern the configuration of the supply network, and the cost results produced by the different scenarios. Then, for the scenario with the lowest seed cost at the biofuel production unit gate, the results of the variation in the maximum number of collection points that can be opened are presented and discussed.

\subsection{Results of the Implementation of the Four Scenarios}

Supply network configuration: For each scenario, the result of the pre-processing location, total harvested surface area, the number of chosen biomass harvesting sites and number of chosen collection points are presented in Table 5. In scenarios 1 and 2, pre-processing always takes place at the collection points. The configuration of the supply network is the same in the scenarios with donkey carts (scenarios 1 and 3). The configuration of the supply network is also the same in the scenarios with tricycles (scenarios 2 and 4). These configuration for the scenarios with tricycles and carts are presented in Figure 2. The total harvested surface area, the number of chosen biomass harvesting sites and chosen collection points in the scenarios with carts is higher than in those with tricycles.

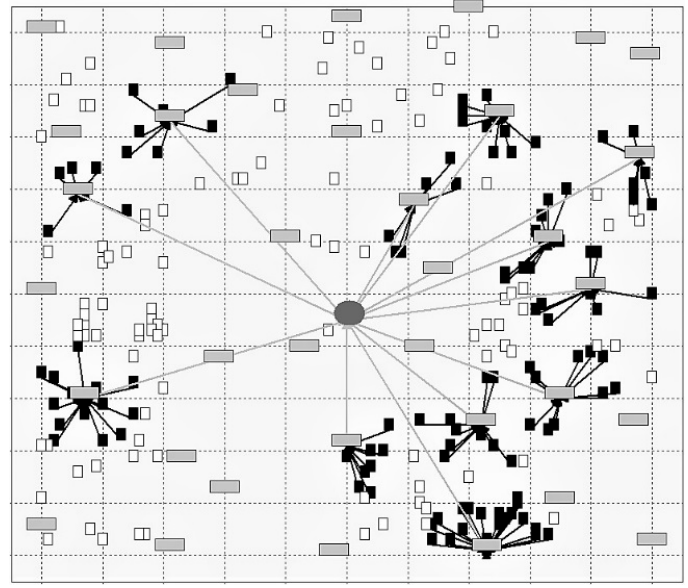

The supply network in scenario 1

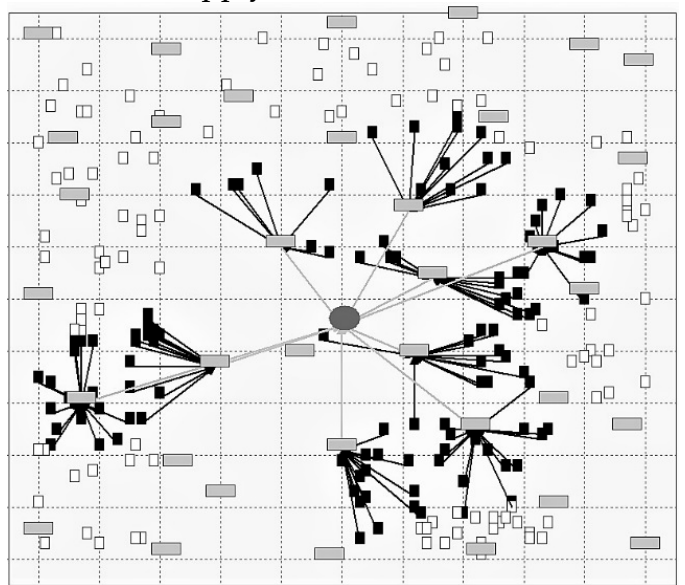

The supply network in scenario 3

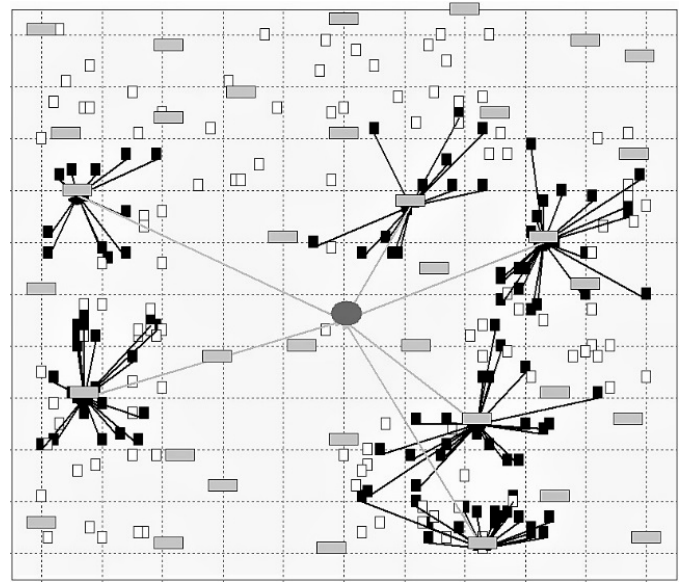

The supply network in scenario 2

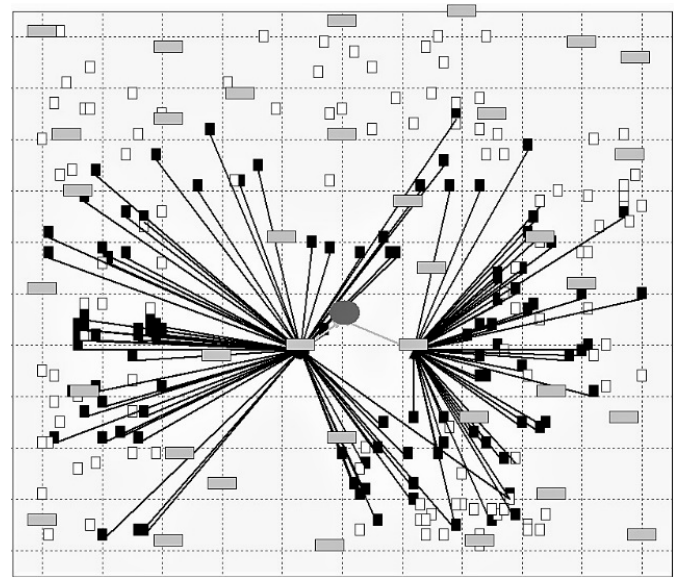

The supply network in scenario 4

$$
\begin{aligned}
& \square \text { Chosen biomass harvesting site } \\
& \square \text { Non-chosen biomass harvesting site } \\
& \text { Biofuel production unit } \\
& \text { Collection point }
\end{aligned}
$$

Figure 2. The supply network in scenarios 1-4. 
Table 5. Results of the supply network configuration.

\begin{tabular}{ccccc}
\hline Scenarios & $\begin{array}{c}\text { Location of } \\
\text { Pre-Processing }\end{array}$ & $\begin{array}{c}\text { Numbers of Chosen } \\
\text { Biomass Harvesting Sites }\end{array}$ & $\begin{array}{c}\text { Numbers of Chosen } \\
\text { Collection Points }\end{array}$ & $\begin{array}{c}\text { Total Harvested } \\
\text { Surface Area (ha) }\end{array}$ \\
\hline Scenario 1 & Collection points & 119 & 12 & 1181.3 \\
Scenario 2 & Collection points & 109 & 6 & 1089.8 \\
Scenario 3 & Biofuel production unit & 117 & 9 & 1167.2 \\
Scenario 4 & Biofuel production unit & 107 & 2 & 1079.8 \\
\hline
\end{tabular}

Cost results in the four scenarios are presented in Figure 3. Harvesting and pre-processing costs represent the costs per $\mathrm{kg}$ of B. aegyptiaca fruits. Transport, handling, and storage costs represent the costs per kg of B. aegyptiaca seed.

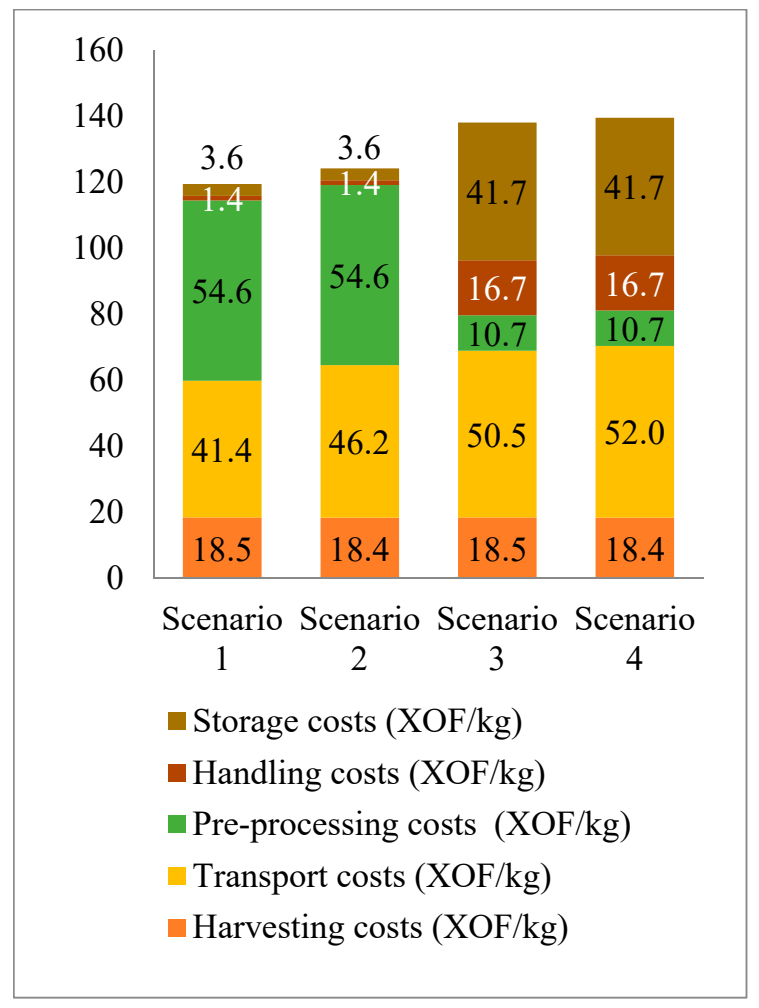

Figure 3. Cost results in the four scenarios.

The cost price of $B$. aegyptiaca seeds at the biofuel production unit gate fluctuates between $119.5 \mathrm{XOF} / \mathrm{kg}$ (scenario 1) and $139.5 \mathrm{XOF} / \mathrm{kg}$ (scenario 4). The lowest seed cost prices at the biofuel production unit gate as well as the lowest costs of all the other supply operations except harvesting and pre-processing are found in the scenarios where pre-processing takes place at the collection points (scenarios 1 and 2). Transport costs fluctuate between $41.4 \mathrm{XOF} / \mathrm{kg}$ in scenario 1 and $52 \mathrm{XOF} / \mathrm{kg}$ in scenario 4 . Transport costs represent about $35 \%$ of seed cost price at the biofuel production unit gate in the four scenarios. Harvesting costs are the same in all the scenarios and represent about $15 \%$ of the seed costs at the biofuel production unit in all the scenarios.

Preprocessing costs represent respectively $45 \%$ and $8 \%$ of the seed cost price at the biofuel production unit gate in scenarios 1 and 2 and in scenarios 3 and 4 . Storage and handling costs represent respectively $4 \%$ and $32 \%$ of the seed costs at the biofuel production unit in scenarios 1 and 2 and in scenarios 3 and 4 . It can be seen that scenarios 1 and 2 pre-processing costs are four times higher, and storage and handling costs are more than 10 times higher than the same items cost in scenarios 3 and 4 . 


\subsection{Discussion}

According to the results presented above, the scenarios with donkey carts (scenarios 1 and 3) have the highest number of chosen biomass harvesting sites and the highest number of chosen collection points. These results can be explained by the short distance travelled by the cart each day $(20 \mathrm{~km})$ compared to the distance travelled by the tricycle per day $(160 \mathrm{~km})$. Indeed, when the tricycles are used, the model is not constrained by short travel distances. Thus, collection points that have the highest fruit yields and are simultaneously located closest to the biofuel production unit and biomass harvesting sites are chosen.

Despite the performance of the tricycle, in scenario 1 the carts that are used have the lowest seed cost price and the lowest transport cost. This can be explained by the fixed costs of the motor tricycles, which are 7.7 times higher than the carts fixed costs (Table 3).

Transport costs between biomass harvesting sites and collection points are mainly affected by the purchase price of the means of transport when motor tricycles are used. When carts pulled by animals are used, transport costs between biomass harvesting sites and collection points are mainly affected by the operating costs of transportation.

High pre-processing costs in the scenarios with pre-processing at the collection points (scenarios 1 and 2), are due to the high cost of manual pre-processing at the collection points. Despite these high pre-processing costs, pre-processing always takes place at the collection points regardless of the means of transport in scenarios where the model is not constrained to choose only one pre-processing location (scenarios 1 and 2). This is due to the fact that less amounts of biomass have to be transported, handled and stored when the pre-processing takes place at the collection points. Indeed, seeds represent only $10 \%$ of the whole B. aegyptiaca fruit weight. Therefore, when pre-processing is located at the collection points, the quantities of biomass to be transported are divided by 10 .

Pre-processing is manual at the collection points because access to electricity is difficult in rural areas and because to date, mechanical pre-processing of B. aegyptiaca is not well developed. Therefore, improving $B$. aegyptiaca fruit pre-processing operations by developing affordable pre-processing machines could significantly reduce seeds cost prices at the biofuel production unit. E. Mamman et al. and Aviara et al. [37] had already addressed this difficulty to manually perform B. aegyptiaca de-hulling. They have indeed worked on the physical properties of the B. aegyptiaca nuts in order to allow the development of machines facilitating fruit de-hulling. Another aspect concerning pre-processing is depulping, which until now consumed significant amounts of water (more than $2 \mathrm{~m}^{3} / \mathrm{t}$ ), especially when the rainfall of the Sahelian regions is taken into consideration. The limited access to water in Sahelian climates could therefore be a brake on the exploitation of B. aegyptiaca in these regions.

To conclude the four scenarios, scenario 1 is the best because pre-processing takes place at the collection points and also because carts pulled by animals are used for feedstock transportation between biomass harvesting sites and collection points. Scenario 1 which produced the lowest total cost was run again by varying the value of the maximum number of collection points that can be opened. Scenario 1 was intentionally re-run to observe the influence (on the supply costs and on the network configuration) of the reduction in the maximum number of collection points that can be opened. The results are presented and discussed in the following section of the paper.

\subsection{Results and Discussion of the Variation in the Maximum Number of Collection Points That Can Be Opened}

The results of the variation of the maximum number of collection points that can be opened are presented in Table 6 and Figure 4.

These results show that when the maximum number of collection points is under 4, no solution is found. This can be explained by the fact that the organization of biomass harvesting sites and of collection points does not allow 3, 2, or 1 gathering point(s) to fulfill the demand for feedstock by the biofuel production unit. 
When the maximum number of gathering points that can be opened is between 4 and 12, feedstock cost prices and transport costs decrease when the maximum number of collection points that can be opened increase (see Figure 4). This result can be explained by the fact that the model is forced to choose biomass harvesting sites, which are located at increasingly far distances when the maximum number of collection points that can be opened decreases. Indeed, the maximum distance between the farthest biomass harvesting site from a gathering point decreases from $18 \mathrm{~km}$ to $10.8 \mathrm{~km}$ when the number of collection points increases from 4 to 12. Moreover, the percentage of biomass harvesting sites at a distance equal to or greater than $11 \mathrm{~km}$ also decreases from $45 \%$ to $0 \%$ when the number of collection points increases from 4 to 12 . This can be seen in Table 6 .

When the maximum number of collection points that can be opened is equal to or greater than 12 , the costs and logistics network configurations remain constant. These costs and logistics network configuration are exactly the same as the configuration of the logistics network and costs found for the maximum number of gathering points equal to 12 (optimum value found for scenario 1 in the above paragraph). This result implies that without any constraint on the number of collection points, 12 collection points are sufficient and optimal for feedstock collection. One more collection point would be useless. This confirms the model's performance in locating and choosing the optimal collection points.

It can be learned from this variation in the number of collection points that when carts pulled by animals (or any other means of transportation having a low velocity and a low load capacity) are used, a high number of collection points helps reducing feedstock cost prices. These reductions in costs are induced by the choice of biomass harvesting sites closer to collection points.

Table 6. Results of the reduction in the maximum number of collection points (GP) that can be opened.

\begin{tabular}{cccc}
\hline Number of GP & Maximum Distance & Distance $>\mathbf{1 1} \mathbf{k m}$ & Distance $<\mathbf{1 1} \mathbf{~ k m}$ \\
\hline 4 GP & $18 \mathrm{~km}$ & $45 \%$ & $55 \%$ \\
5 GP & $15.7 \mathrm{~km}$ & $36 \%$ & $64 \%$ \\
6 GP & $14.1 \mathrm{~km}$ & $29 \%$ & $71 \%$ \\
7 GP & $13 \mathrm{~km}$ & $23 \%$ & $77 \%$ \\
8 GP & $12.7 \mathrm{~km}$ & $14 \%$ & $86 \%$ \\
9 GP & $11.7 \mathrm{~km}$ & $8 \%$ & $92 \%$ \\
10 GP & $11.4 \mathrm{~km}$ & $2 \%$ & $98 \%$ \\
11 GP & 10.8 & $0 \%$ & $100 \%$ \\
12 GP & 10.8 & $0 \%$ & $100 \%$ \\
\hline
\end{tabular}

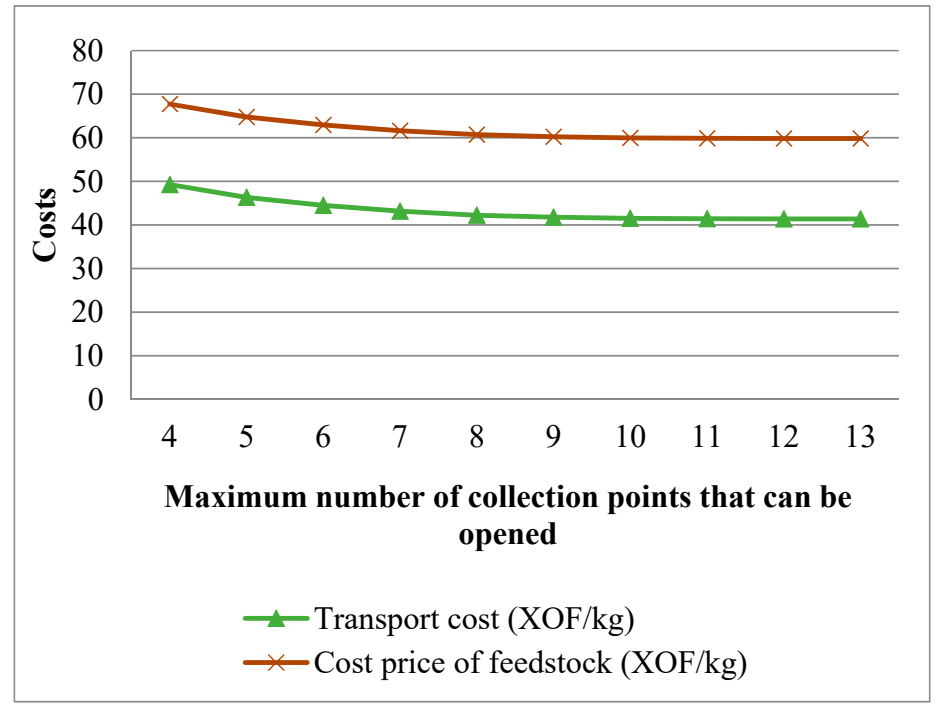

Figure 4. Variation in the cost price of the feedstock at the biofuel production unit and in the transport cost. 


\section{Conclusions}

A mathematical model for making decisions regarding the wild non-timber forest products supply chain for biofuel production is herein described. It has been applied to the Balanites aegyptiaca seed supply chain.

Based on the characteristics of the studied region and considering different means of transport and different pre-processing options, the model determines the optimal supply network configuration for feedstock supply to a biofuel production unit.

The model was implemented as a theoretical case study in the sub-Sahelian region of Burkina Faso. The results of the case study implementation show that in such a context, more than $35 \%$ of the cost price of seeds at the biofuel production unit gate is the cost of transport. Pre-processing, handling, and storage costs represent about $50 \%$ of the cost price of the seeds. In the best scenario, the cost of collecting feedstock represents more than $70 \%$ of the transport costs. Due to the high fixed costs of the motor tricycles, the most efficient way to transport biomass from the biomass harvesting sites to the collection points is by using animal drawn carts. Motor tricycles could be profitable for the transport of biomass if their purchasing cost could be reduced, as they can travel faster and have a higher load capacity than carts. Moreover, when the number of collection points is limited, tricycles could be more profitable because they enable fewer collection points than do carts.

Despite the fact that the cost of motorized pre-processing at the biofuel production unit is the lowest, pre-processing is better performed before transport. This is due to the very low weight of B. aegyptiaca seed compared to the weight of the whole fruit. Consequently, improving B. aegyptiaca fruit pre-processing operations by developing affordable mechanical pre-processing machines could significantly reduce the cost of seeds at the biofuel production unit. This would indeed simultaneously reduce biomass pre-processing and transportation costs.

A serious and controlled exploitation of B. aegyptiaca could make it a good feedstock for producing biofuel in Sahelian areas where the soil and climatic conditions are not suitable for growing the plants commonly used for biofuel production. The produced biofuels could be used for electrifying rural areas of Sahelian countries such as Burkina Faso, Mali, Niger, and Chad.

The next step in this research will be the study of Balanites aegyptiaca reverse logistics. The aim is to examine the benefits that a reverse supply chain might have on the feedstock cost prices.

Author Contributions: Conceptualization, J.B., M.S., D.A., D.R. and S.K.O.; Methodology, L.D.F.B., M.S., D.R. and D.A.; Software, L.D.F.B.; Validation, D.A. and S.K.O.; Formal Analysis, L.D.F.B.; Investigation, L.D.F.B.; Resources, M.S., J.B. and D.A.; Data Curation, L.D.F.B., M.S. and J.B.; Writing-Original Draft Preparation, L.D.F.B.; Writing-Review \& Editing, Daniel Roy, M.S. and J.B.; Visualization, L.D.F.B.; Supervision, D.A. and S.K.O.; Project Administration, D.A. and S.K.O.; Funding Acquisition, J.B. and M.S.

Funding: This research received no external funding.

Acknowledgments: This paper is expanded and improved from the conference paper. Sawadogo, M.; Bambara, L.D.F.; Blin, J.; Anciaux, D.; Roy, D. Optimization of Balanites aegyptiaca seeds supply chain for biofuel production in West Africa sahelian regions. In Proceedings of the 2017 8th International Renewable Energy Congress (IREC), Amman, Jordan, 21-23 March 2017; pp. 1-5, doi:10.1109/IREC.2017.7926017.

Conflicts of Interest: The authors declare no conflicts of interest.

\section{References}

1. IEA. World Energy Outlook 2017; Organisation for Economic Co-operation and Development, OECD: Paris, France, 2017.

2. Sulaiman, C.; Abdul-Rahim, A.S.; Mohd-Shahwahid, H.O.; Chin, L. Wood fuel consumption, institutional quality, and forest degradation in sub-Saharan Africa: Evidence from a dynamic panel framework. Ecol. Indic. 2017, 74, 414-419. [CrossRef]

3. Giannini Pereira, M.; Vasconcelos Freitas, M.A.; da Silva, N.F. The challenge of energy poverty: Brazilian case study. Energy Policy 2011, 39, 167-175. [CrossRef] 
4. Amigun, B.; Musango, J.K.; Stafford, W. Biofuels and sustainability in Africa. Renew. Sustain. Energy Rev. 2011, 15, 1360-1372. [CrossRef]

5. Gasparatos, A.; Lee, L.Y.; Von Maltitz, G.P.; Mathai, M.V.; Puppim de Oliveira, J.A.; Willis, K.J. Biofuels in Africa: Impacts on Ecosystem Services, Biodiversity and Human Well-Being; United Nations University Institute of Advanced Studies: Tokyo, Japan, 2012.

6. Blin, J.; Brunschwig, C.; Chapuis, A.; Changotade, O.; Sidibe, S.S.; Noumi, E.S.; Girard, P. Characteristics of vegetable oils for use as fuel in stationary diesel engines: Towards specifications for a standard in West Africa. Renew. Sustain. Energy Rev. 2013, 22, 580-597. [CrossRef]

7. Adaramola, M.S.; Quansah, D.A.; Agelin-Chaab, M.; Paul, S.S. Multipurpose renewable energy resources based hybrid energy system for remote community in northern Ghana. Sustain. Energy Technol. Assess. 2017, 22, 161-170. [CrossRef]

8. Franco, A.; Shaker, M.; Kalubi, D.; Hostettler, S. A review of sustainable energy access and technologies for healthcare facilities in the Global South. Sustain. Energy Technol. Assess. 2017, 22, 92-105. [CrossRef]

9. Bart, J.C.J.; Palmeri, N.; Cavallaro, S. 6-Emerging new energy crops for biodiesel production. In Biodiesel Science and Technology; Bart, J.C.J., Palmeri, N., Cavallaro, S., Eds.; Woodhead Publishing Series in Energy; Woodhead Publishing: Sawston, UK, 2010; pp. 226-284, ISBN 978-1-84569-591-0.

10. Patel, N.K.; Shah, S.N. 11-Biodiesel from Plant Oils. In Food, Energy, and Water; Ahuja, S., Ed.; Elsevier: Boston, MA, USA, 2015; pp. 277-307, ISBN 978-0-12-800211-7.

11. Ndoye, M.; Diallo, I.; Gassama/Dia, Y.K. Reproductive biology in Balanites aegyptiaca (L.) Del., a semi-arid forest tree. Afr. J. Biotechnol. 2004, 3, 40-46.

12. Chapagain, B.; Wiesman, Z. Variation in diosgenin level in seed kernels among different provenances of Balanites aegyptiaca Del (Zygophyllaceae) and its correlation with oil content. Afr. J. Biotechnol. 2005, 4. [CrossRef]

13. Okia, C.A.; Kwetegyeka, J.; Okiror, P.; Kimondo, J.M.; Teklehaimanot, Z.; Obua, J. Physico-chemical characteristics and fatty acid profile of desert date kernel oil. Afr. Crop Sci. J. 2013, 21, 723-734.

14. Chapagain, B.P. Characterization of Desert Date (Balanites Aegyptiaca) Saponins and Their Biological Activities; Ben-Gurion University of the Negev: Beer-Sheva, Israel, 2006.

15. Varshney, A.; Anis, M. Trees: Propagation and Conservation: Biotechnological Approaches for Propagation of a Multipurpose Tree, Balanites Aegyptiaca Del.; Springer: New Delhi, India, 2014; ISBN 978-81-322-1701-5.

16. Boffa, J.-M. Les Parcs Agroforestiers en Afrique Subsaharienne; Food \& Agriculture Organization: Rome, Italy, 2000; ISBN 978-92-5-204376-8.

17. Angelsen, A.; Wunder, S. Exploring the forest-poverty link: Key concepts, issues and research implications. Cent. Int. For. Res. 2003. [CrossRef]

18. Pouliot, M.; Treue, T. Rural People's Reliance on Forests and the Non-Forest Environment in West Africa: Evidence from Ghana and Burkina Faso. World Dev. 2013, 43, 180-193. [CrossRef]

19. Yunus, M.M.; Zuru, A.A. Kinetics study of balanites aegyptiaca oil transesterification for the production of biodiesel. Niger. J. Chem. Res. 2017, 22, 9-19.

20. Dass, P.M.; Louis, H.; Alheri, A.; Amos, P.I.; Bifam, M.; Ago, M.A. Production of Biodiesel Oil from Desert Dates (Balanites aegyptiaca) Seeds Oil Using a Hetrogeneous Catalyst Produced from Mahogany (Khaya senegalensis) Fruit Shells. Anal. Chem. Indian J. 2018, 18, 1-12.

21. Naik, N.S.; Balakrishna, B. Assessment of toxic content in Balanites aegyptiaca seed cake and use of enzymatic-catalysed biodiesel in diesel engine. Int. J. Ambient Energy 2018, 39, 488-495. [CrossRef]

22. Naik, N.S.; Balakrishna, B. Experimental evaluation of a diesel engine fueled with Balanites aegyptiaca (L.) Del biodiesel blends. Biofuels 2016, 7, 603-609. [CrossRef]

23. Sunil Naik, N.; Balakrishna, B. Effects of EGR on performance and emissions of a diesel engine fuelled with balanites aegyptiaca/diesel blends. Int. J. Sustain. Eng. 2017, 11, 150-158. [CrossRef]

24. Council, N.R. Lost Crops of Africa: Volume III: Fruits; The National Academies Press: Washington, DC, USA, 2008; ISBN 978-0-309-10596-5.

25. Kumar, D.; Singh, B. Role of biomass supply chain management in sustainable bioenergy production. Biofuels 2017, 0, 1-11. [CrossRef]

26. Rentizelas, A.A. 2-Biomass supply chains. In Biomass Combustion Science, Technology and Engineering; Rosendahl, L., Ed.; Woodhead Publishing Series in Energy; Woodhead Publishing: Sawston, UK, 2013; pp. 9-35, ISBN 978-0-85709-131-4. 
27. Sultana, A.; Kumar, A. Development of tortuosity factor for assessment of lignocellulosic biomass delivery cost to a biorefinery. Appl. Energy 2014, 119, 288-295. [CrossRef]

28. Chapagain, B.P.; Yehoshua, Y.; Wiesman, Z. Desert date (Balanites aegyptiaca) as an arid lands sustainable bioresource for biodiesel. Bioresour. Technol. 2009, 100, 1221-1226. [CrossRef] [PubMed]

29. Hall, J.B. Ecology of a key African multipurpose tree species, Balanites aegyptiaca (Balanitaceae): The state-of-knowledge. For. Ecol. Manag. 1992, 50,1-30. [CrossRef]

30. Sawadogo, M.; Bambara, L.D.; Blin, J.; Anciaux, D.; Roy, D. Optimization of Balanites aegyptiaca seeds supply chain for biofuel production in West Africa sahelian regions. In Proceedings of the 8th International Renewable Energy Congress (IREC), Amman, Jordan, 21-23 March 2017; pp. 1-5.

31. Lhoste, P.; Havard, M.; Vall, É. La traction Animale, 1st ed.; QUAE: Versailles, France, 2010.

32. AMASSA, "Manuel d'information sur le transport des produits agricoles au Mali". AMASSA Afrique Verte Mali: Bamako, 2009. Available online: http://www.afriqueverte.org/r2_public/media/fck/File/ Documentation/Outils_information/cout-transport-cereales-au-mali-2009.pdf (accessed on 6 January 2016).

33. Okia, C.A. Balanites Aegyptiaca: A Resource for Improving Nutrition and Income of Dryland Communities in Uganda. Ph.D. Thesis, Prifysgol Bangor University, Bangor, UK, 2010.

34. SP/CPSA. Etude-Diagnostic sur L'organisation, les Performances et Perspectives de la Filière Niébé Burkinabè; Ministère de l'Agriculture: Ouagadougou, Burkina Faso, 2002.

35. Allard, B. Evaluation de la Rentabilité Economique de la Filière Jatropha dans la Région de Teriya Bugu (Mali). 2010. Available online: https://www.fichier-pdf.fr/2012/05/31/2010-estudio-hilera-agro-carburantejatropha/ (accessed on 12 March 2016).

36. Aviara, N.A.; Mamman, E.; Umar, B. Some Physical Properties of Balanites Aegyptiaca Nuts. Biosyst. Eng. 2005, 92, 325-334. [CrossRef]

37. Mamman, E.; Umar, B.; Aviara, N.A. Effect of Moisture Content and Loading Orientation on the Mechanical Properties of Balanites Aegyptiaca Nuts. 2005. Available online: http:/ /www.cigrjournal.org/index.php/ Ejounral/article/view/602 (accessed on 20 June 2016).

(C) 2018 by the authors. Licensee MDPI, Basel, Switzerland. This article is an open access article distributed under the terms and conditions of the Creative Commons Attribution (CC BY) license (http:/ / creativecommons.org/licenses/by/4.0/). 